\title{
ROLE OF A5 NORADRENERGIC NEURONS IN THE CHEMOREFLEX CONTROL OF RESPIRATORY AND SYMPATHETIC ACTIVITIES IN UNANESTHETIZED CONDITIONS
}

\author{
CAMILA L. TAXINI, ${ }^{a}$ THIAGO S. MOREIRA, ${ }^{b}$ \\ ANA C. TAKAKURA, ${ }^{\circ}$ KÊNIA C. BÍCEGO, ${ }^{a}$ \\ LUCIANE H. GARGAGLIONI ${ }^{2 * \dagger}$ AND \\ DANIEL B. ZOCCAL ${ }^{\mathrm{d} * \dagger}$ \\ ${ }^{a}$ Department of Morphology and Animal Physiology, São Paulo \\ State University (UNESP), Jaboticabal, SP, Brazil \\ ${ }^{\mathrm{b}}$ Department of Physiology and Biophysics, Institute of \\ Biomedical Sciences, University of São Paulo (USP), São Paulo, SP, \\ Brazil \\ ${ }^{\mathrm{C}}$ Department of Pharmacology, Institute of Biomedical \\ Sciences, University of São Paulo (USP), São Paulo, SP, Brazil \\ ${ }^{\mathrm{d}}$ Department of Physiology and Pathology, School of Dentistry, \\ São Paulo State University (UNESP), Araraquara, SP, Brazil
}

\begin{abstract}
The A5 area at the ventrolateral pons contains noradrenergic neurons connected with other medullary areas involved in the cardiorespiratory control. Its contribution to the cardiorespiratory regulation was previously evidenced in anesthetized conditions. In the present study, we investigated the involvement of the A5 noradrenergic neurons to the basal and chemoreflex control of the sympathetic and respiratory activities in unanesthetized conditions. A5 noradrenergic neurons were lesioned using microinjections of anti-dopamine $\beta$-hydroxylase saporin (anti-DßH-SAP). After 7-8 days, we evaluated the arterial pressure levels, heart rate and minute ventilation in freely moving adult rats $(280-350 \mathrm{~g})$ as well as recorded from thoracic sympathetic (tSN) and phrenic nerves (PN) using the arterially perfused in situ preparation of juvenile rats $(80$ $90 \mathrm{~g}$ ). Baseline cardiovascular, sympathetic and respiratory parameters were similar between control $(n=7-8)$ and A5lesioned rats $(n=5-6)$ in both experimental preparations. In adult rats, lesions of A5 noradrenergic neurons did not modify the reflex cardiorespiratory adjustments to hypoxia
\end{abstract}

\footnotetext{
*Corresponding authors. Address: Department of Morphology and Animal Physiology - FCAV, São Paulo State University (UNESP), Via de acesso Paulo Donato Castellane s/n, 14870-000 Jaboticabal, Brazil. Fax: +55-16-32024275 (L. H. Gargaglioni). Department of Physiology and Pathology - FOAR, São Paulo State University (UNESP), Rua Humaitá 1680, 14801-903 Araraquara, Brazil. Fax: +55-16-33016488 (D. B. Zoccal).

E-mail addresses: lucihel@fcav.unesp.br (L. H. Gargaglioni), zoccal@foar.unesp.br (D. B. Zoccal).

$\dagger$ Joint last authors.

Abbreviations: Anti-D $\beta \mathrm{H}-\mathrm{SAP}$, saporin conjugated to anti-dopamine beta-hydroxylase; bpm, bursts per minute; E2, second stage of expiration; $\mathrm{f}_{R}$, respiratory frequency; GABA, $\gamma$-aminobutyric acid; IgG$\mathrm{SAP}$, saporin conjugated to immunoglobulin G; KCN, potassium cyanide; MAP, mean arterial pressure; PAP, pulsatile arterial pressure; PN, phrenic nerve; post-I, post-inspiration; RVLM, rostral ventrolateral medulla; $\mathrm{TH}$, tyrosine hydroxylase; tSN, thoracic sympathetic; $\mathrm{V}_{E}$, pulmonary ventilation; $\mathrm{V}_{T}$, tidal volume.
}

$\left(7 \% \mathrm{O}_{2}\right)$ and hypercapnia $\left(7 \% \mathrm{CO}_{2}\right)$. In the in situ preparations, the sympatho-excitation, but not the PN reflex response, elicited by either the stimulation of peripheral chemoreceptors ( $\Delta \mathrm{tSN}$ : $110 \pm 12 \%$ vs $58 \pm 8 \%, P<0.01$ ) or hypercapnia ( $\Delta \mathrm{tSN}$ : $9.5 \pm 1.4 \%$ vs $3.9 \pm 1.7 \%, P<0.05$ ) was attenuated in A5-lesioned rats compared to controls. Our data demonstrated that A5 noradrenergic neurons are part of the circuitry recruited for the processing of sympathetic response to hypoxia and hypercapnia in unanesthetized conditions. (c) 2017 IBRO. Published by Elsevier Ltd. All rights reserved.

Key words: sympathetic activity, respiration, hypoxia, hypercapnia, noradrenergic neurons.

\section{INTRODUCTION}

Endogenous noradrenaline release is required for adequate control of the cardiorespiratory functions (Schreihofer et al., 2000; Dawid-Milner et al., 2001; Swoap et al., 2004; Viemari et al., 2004b; Li and Nattie, 2006; Doi and Ramirez, 2010; Oliveira et al., 2016). During development, an increase in the tyrosine-hydroxylase activity in pontine-medullary neurons is an important step for the maturation of respiratory system (Bezin et al., 1994; Lagercrantz et al., 1994). In adults, lesions of the brainstem catecholaminergic neurons reduce resting arterial pressure and breathing frequency, impair hypoxiainduced sympathoexcitatory response and depress the ventilatory response to hypercapnia (Schreihofer and Guyenet, 2000; Li and Nattie, 2006). It has been evidenced that pontine catecholaminergic neuronal groups are essential for the appropriate basal and reflex regulation of cardiorespiratory functions (Guyenet et al., 1993; Biancardi et al., 2008; Taxini et al., 2011; Lopez Gonzalez et al., 2013). Among them, the $A 5$ area, located within the ventrolateral pons, is suggested as an important nucleus involved in cardiorespiratory control (Loewy et al., 1979b; Byrum and Guyenet, 1987; Dobbins and Feldman, 1994).

The A5 noradrenergic cells project to the presympathetic neurons of the rostral ventrolateral medulla (RVLM) as well as to the pre-ganglionic sympathetic neurons of the spinal cord (Loewy et al., 1979a; Byrum and Guyenet, 1987; Huangfu et al., 1991). However, functional evidence about the contribution of the A5 noradrenergic neurons to the regulation of sympathetic outflow is dubious, with studies reporting that A5 stimulation 
produces complex cardiovascular responses, including renal sympathetic activation, increases and decreases in the arterial pressure and muscle vasodilatation or no effect (Loewy et al., 1979b; Neil and Loewy, 1982; Stanek et al., 1984; Woodruff et al., 1986; Kanbar et al., 2011). Moreover, although studies reported that stimulation of peripheral chemoreceptors promotes the activation of A5 cells (Huangfu et al., 1991; Hirooka et al., 1997; Kanbar et al., 2011), lesions of the A5 noradrenergic neurons did not modify the sympathoexcitatory response to hypoxia (Taxini et al., 2011). These contrasting data may be associated with the fact that some of these studies were performed on anesthetized animals - an experimental condition that may affect the mechanisms responsible for the control of sympathetic activity and the processing of reflex responses (Machado and Bonagamba, 1992; Accorsi-Mendonca et al., 2007; Massey et al., 2015), or due to the lesion protocol, which was not limited to the A5 noradrenergic neurons.

With respect to breathing regulation, anatomical studies reported that the A5 cells present respiratoryrelated pattern of discharge (Guyenet et al., 1993) and are connected to the bulbospinal respiratory premotor neurons (Dobbins and Feldman, 1994). At early life, the A5 area appears to exert a tonic inhibitory control on breathing frequency, at least in in vitro reduced preparations (Hilaire et al., 1989). In adult anesthetized and vagotomized rats, it was evidenced that pharmacological inhibition of the cells of dorsolateral pons, including the A5 area, promotes an apneustic phrenic burst pattern (Jodkowski et al., 1994) while the stimulation of the same region prolongs the expiratory time (Jodkowski et al., 1997). In addition, it was demonstrated that respiratorymodulated neurons of the A5 are stimulated by hypoxia (Guyenet et al., 1993) and hypercapnia (Kanbar et al., 2011) and the inhibition of the A5 area attenuates the chemoreflex respiratory responses (Taxini et al., 2011). These studies indicate that the A5 region is involved in the control of respiratory frequency, at least under certain experimental conditions. However, there is no evidence whether the A5 noradrenergic neurons play a role in the control respiratory rhythm in unanesthetized conditions.

Previous studies have attempted to investigate the role of A5 neurons in the cardiovascular control of unanesthetized conditions (Maiorov et al., 2000; Madden and Sved, 2003; Kvetnansky et al., 2006; Vianna and Carrive, 2010). However, there is a lack of selectivity regarding the neuronal phenotype targeted in the A5 region. Moreover, none of these previous studies have explored the possible involvement of A5 neurons in the respiratory control. Accordingly, the present study was designed to investigate the role of the A5 noradrenergic neurons in the control of respiratory rhythm and sympathetic outflow in the absence of depressant effects of anesthesia. To reach this goal, we performed chemical lesions of the A5 noradrenergic cells using the ribosomal toxin saporin conjugated with a monoclonal antibody associated to the catecholamine-specific enzyme dopamine $\beta$ hydroxylase (Anti-D $\beta \mathrm{H}-\mathrm{SAP}$ ) and evaluated resting and chemoreflex control of cardiorespiratory function in unanesthetized, freely moving adult animals as well as in the decerebrated arterially perfused in situ preparations of juvenile rats.

\section{EXPERIMENTAL PROCEDURES}

\section{Animals and Ethical approval}

Experiments were performed on male Wistar adult rats (280-360 g, in vivo experiments) and on male Holtzman juvenile rats $(75-80 \mathrm{~g}$, in situ experiments). All protocols were performed in accordance with the Ethical Principles of Animal Experimentation and were approved by the Ethics Committee on Animal Experimentation of the School of Agriculture Sciences of Jaboticabal (Protocol: 004449/10) as well as of the School of Dentistry of Araraquara (Protocol: 18/2014). The animals received food and water ad libitum and were maintained at conditions of controlled temperature $\left(22 \pm 1^{\circ} \mathrm{C}\right)$ and humidity $(50-55 \%)$, with light-dark cycles of $12 \mathrm{~h}$ (lights on at 06:30 am).

\section{Chemical lesions of A5 noradrenergic neurons}

Lesions of the A5 noradrenergic neurons were achieved using anti-dopamine $\beta$-hydroxylase saporin (anti- $\mathrm{D} \beta \mathrm{H}$ SAP), as previously described (Taxini et al., 2011). Adult and juvenile rats were anesthetized with ketamine (80 $\mathrm{mg} \mathrm{kg}^{-1}$, intraperitoneally, ip) and xylazine $\left(7 \mathrm{mg} \mathrm{kg}^{-1}\right.$, ip) and positioned in a stereotaxic apparatus (Kopf Instruments, Kent, England). After a longitudinal incision in the skin and subcutaneous tissue, the cranial bone was exposed and the sutures were identified for reference to target the A5 region using the following stereotaxic coordinates: 0.8 or $1.2 \mathrm{~mm}$ caudal to lambda, 1.5 or $2.3 \mathrm{~mm}$ lateral to midline and 9.0 or $9.9 \mathrm{~mm}$ below the bone surface, respectively in juvenile and adult rats. Bilateral microinjections of anti-D $\beta \mathrm{H}-\mathrm{SAP}$ (4.2 ng; Advanced Targeting Systems, San Diego, CA, USA) or IgG-SAP (control; Advanced Targeting Systems, San Diego, CA, USA) were performed using a $30-G$ stainless needle coupled to a Hamilton syringe. The microinjection volumes were $100 \mathrm{~nL} /$ side in adult rats and $50 \mathrm{~nL} /$ side in juvenile rats, which were performed slowly (during $2 \mathrm{~min}$ ) with the aid of a pump (Model 310, Stoelting Co., IL, USA) to minimize drug diffusion. After the injections, the subcutaneous and muscular tissues were sutured and the animal received antibiotic (enrofloxacin, $10 \mathrm{mg} \mathrm{kg}^{-1}$, intramuscularly, im) and analgesic (flunixinmeglumine, $2.5 \mathrm{mg} \mathrm{kg}^{-1}$, subcutaneously, sc). At the end of surgical procedures, the animals were monitored until regain consciousness and received water and food ad libitum. The animals were then kept for a period of one week for recovery and toxin action (Taxini et al., 2011).

\section{Determination of pulmonary ventilation $\left(V_{E}\right)$}

Whole body plethysmography (Bartlett and Tenney, 1970) was used to measure $V_{E}$ in adult unanesthetized animals, as previous described (Biancardi et al., 2008; Taxini et al., 2013). One day before the experiments, animals were anesthetized with ketamine $\left(80 \mathrm{mg} \mathrm{kg}^{-1}\right.$, ip) and xylazine $\left(7 \mathrm{mg} \mathrm{kg}^{-1}\right.$, ip) and a small incision was 
performed in the abdominal wall to implant a temperature recorder (data-loggers; SubCue, Calgary, AT, CA) for body temperature measurements - used to calculate the tidal volume. After surgery, animals were treated with antibiotic (enrofloxacin, $10 \mathrm{mg} \mathrm{kg}^{-1}$, im) and analgesic (flunixin meglumine, $2.5 \mathrm{mg} \mathrm{kg}^{-1}, \mathrm{sc}$ ) and monitored until regain consciousness. Twenty-four hours after, the animals were kept in a 5-L chamber ventilated with room air, hypercapnic gas mixture $\left(7 \% \mathrm{CO}_{2}, 21 \% \mathrm{O}_{2}\right.$ and $\mathrm{N}_{2}$ for balance; White Martins, Sertãozinho, Brazil) or a hypoxic gas mixture $\left(7 \% \mathrm{O}_{2}\right.$ and $\mathrm{N}_{2}$ for balance) in low noise conditions. The flow rate $\left(1 \mathrm{~L} \mathrm{~m}^{-1}\right)$ of gases into the chamber was monitored by a flowmeter (Sierra Instruments, Monterey, CA, USA). During measurements, the flow was interrupted and the chamber was sealed for short periods of time (approximately $2 \mathrm{~min}$ ) to record the respiratory-related pressure oscillations using a differential pressure transducer (TSD 160A, Biopac Systems, Santa Barbara, CA, USA). The signals were amplified (DA 100C, Biopac Systems) and acquired on a microcomputer (MP100A-CE, Biopac Systems) at a sampling rate of $1 \mathrm{kHz}$ (Acqknowledge, v. 4.2.3, Biopac Systems). Tidal volume $\left(V_{T}\right)$ and respiratory frequency $\left(f_{R}\right)$ were calculated and used to determine minute ventilation $\left(V_{E}\right)$. $V_{T}$ was determined based on the calibration volume (obtained in every experiment by injecting $1 \mathrm{~mL}$ of air into the chamber) and using an appropriated formula, as previously described (Bartlett and Tenney, 1970).

\section{Measurements of arterial blood pressure, heart rate and body temperature in unanesthetized animals}

In a subgroup of animals, cardiovascular parameters were measured simultaneously to ventilation. To this end, one day before the experiments, the adult rats were anesthetized with ketamine $\left(80 \mathrm{mg} \mathrm{kg}^{-1}\right.$, ip) and xylazine $\left(7 \mathrm{mg} \mathrm{kg}^{-1}\right.$, ip) and a polyethylene catheter (PE-10 connected to PE-50; Clay Adams, Parsippany, NJ, USA) was inserted into the abdominal aorta through the femoral artery for measurements of pulsatile arterial pressure (PAP). The arterial catheter was then tunneled subcutaneously and exteriorized at the animal dorsum. After that, a temperature recorder was also implanted into the abdominal cavity, as previously described. After surgery, animals were treated with antibiotic (enrofloxacin, $10 \mathrm{mg} \mathrm{kg}^{-1}$, im) and analgesic (flunixin meglumine, $2.5 \mathrm{mg} \mathrm{kg}^{-1}, \mathrm{sc}$ ) and monitored until recovered from anesthesia. On the next day, when the animals were recovered from surgical procedures, the arterial catheter was connected to a pressure transducer (TSD 104A; Biopac systems) and to an amplifier (DA 100C; Biopac systems) for the monitoring of PAP in unanesthetized conditions. PAP was recorded using a data acquisition system (MP100 ACE; Biopac systems) at a sampling rate of $1 \mathrm{kHz}$. Mean arterial pressure (MAP) and heart rate (HR) were derived from PAP signals (Acqknowledge, v 4.2.3, Biopac Systems).

\section{In situ working heart-brainstem preparation}

Working heart-brainstem preparations (Paton, 1996) were surgically prepared one week after the microinjections in the A5, as previously described (Zoccal et al., 2008). The animals were initially deeply anesthetized with halothane (AstraZeneca, Cotia, SP, Brazil) until the loss of the paw withdrawal reflex, transected caudal to the diaphragm, submerged in a chilled Ringer solution (in $\mathrm{mM}$ : $\mathrm{NaCl}, 125 ; \mathrm{NaHCO}_{3}, 24 ; \mathrm{KCl}, 3 ; \mathrm{CaCl}_{2}, 2.5 ; \mathrm{MgSO}_{4}$, 1.25; $\mathrm{KH}_{2} \mathrm{PO}_{4}, 1.25$; dextrose, 10) and decerebrated at the precollicular level. Lungs were removed the preparations were then transferred to a recording chamber. The descending aorta was cannulated and perfused retrogradely using a roller pump (Watson-Marlow 502 s, Falmouth, Cornwall, UK) via a double-lumen cannula. The perfusate consisted of Ringer solution containing $1.25 \%$ Polyethylene glycol (an oncotic agent, Sigma, St Louis, USA) and a neuromuscular blocker (vecuronium bromide, 3-4 $\mu \mathrm{g} \mathrm{mL}^{-1}$, Cristália Produtos Químicos Farmacêuticos Ltda., São Paulo, Brazil). This solution was gassed continuously with $5 \% \quad \mathrm{CO}_{2}-95 \% \quad \mathrm{O}_{2}$, warmed to $31-32{ }^{\circ} \mathrm{C}$ and filtered using a nylon mesh (pore size: $25 \mu \mathrm{m}$, Millipore, Billirica, MA, USA). The perfusion pressure was maintained in the range of $50-70 \mathrm{mmHg}$ by adjusting the rate flow to $21-25 \mathrm{~mL} \mathrm{~min}^{-1}$ and by adding vasopressin to the perfusate $(0.6-1.2 \mathrm{nM}$, Sigma, St. Louis, MO, USA).

\section{Nerves recording and data analyses}

Sympathetic and phrenic nerves (PN) were isolated and their activity recorded simultaneously using bipolar glass suction electrodes held in micromanipulators (Narishige, Tokyo, Japan). Left phrenic nerve discharges were recorded from its central end and its rhythmic ramping activity was used to monitor preparation viability. The sympathetic activity was recorded from the thoracic sympathetic chain (tSN) at the level of T10-T12. The signals were amplified, band-pass filtered $(0.1-3 \mathrm{kHz}$; Grass Technologies, Middleton, USA), and acquired with an A/D converter (CED 1401; Cambridge Electronic Design, Cambridge, UK) to a computer using Spike2 software (version 7; Cambridge Electronic Design, Cambridge, UK) at a sampling rate of $5 \mathrm{kHz}$. All nerves were recorded in absolute units $(\mu \mathrm{V})$. At the end of the experiments, the perfusion pump was turned off to determine the electrical noise (after the death of the preparations).

The analyses were carried out on rectified and smoothed signals (time constant of $50 \mathrm{~ms}$ ), and performed off-line using Spike 2 software (CED, Cambridge, UK) after noise subtraction. PN activity was evaluated by its burst frequency and amplitude. PN burst frequency was derived from the time interval between consecutive integrated phrenic peak bursts and expressed in bursts per minute (bpm). Integrated PN burst amplitude was determined (in $\mu \mathrm{V}$ ) by the value difference between the burst peak and the minimal activity observed during expiratory period. Baseline tSN activity was calculated as the mean values (in $\mu \mathrm{V}$ ) of integrated signals. Phrenic-triggered averages of tSN were also generated from 1-3 min epochs to analyze the pattern of tSN across the respiratory cycle. To this, mean tSN activity was measured during inspiration (period coincident with phrenic burst), post-inspiration 
(post-I, first half of expiratory period) and second stage of expiration (E2, second half of expiratory period). The values were then normalized by the maximal tSN observed during late-inspiratory/post-inspiratory phases (100\%), as previously described (Zoccal et al., 2008). The analyses were applied for each preparation and data obtained were pooled together and compared between groups. The changes in the PN amplitude and tSN activity induced by potassium cyanide (KCN) and hypercapnia (see bellow) were expressed as percentage values in relation to basal values prior to the stimuli. The changes in the other parameters were expressed in their original units.

\section{Experimental design}

Unanesthetized adult rats - Seven days after surgery, each animal was individually placed into the plethysmoghraphic chamber $(5 \mathrm{~L})$ and acclimatized for at least $1 \mathrm{~h}$, while the chamber was flushed with humidified room air at $25^{\circ} \mathrm{C}$. After this period, baseline recordings of $\mathrm{V}_{\mathrm{T}}, \mathrm{fR}, \mathrm{MAP}$ and $\mathrm{HR}$ were obtained for 10-15 min. Subsequently, hypercapnic $\left(7 \% \mathrm{CO}_{2}, 21 \%\right.$ $\left.\mathrm{O}_{2}, 81 \% \mathrm{~N}_{2}\right)$ or hypoxic $\left(7 \% \mathrm{O}_{2}, 93 \% \mathrm{~N}_{2}\right)$ gas mixture was flushed separately in the chamber for $30 \mathrm{~min}$. Cardiovascular and ventilatory parameters were evaluated at 10 and 30 min of exposure. Animals were randomly exposed to both hypercapnia and hypoxia, with a time interval of $30 \mathrm{~min}$ between stimuli.

In situ preparations of juvenile rats - After a stabilization period of 20-30 min, baseline sympathetic and phrenic activities were recorded for $15 \mathrm{~min}$. After that, peripheral and central chemoreceptors were stimulated $\mathrm{KCN}$ and hypercapnia, respectively, as previously described (Costa-Silva et al., 2010; Molkov et al., 2011). KCN (0.05\%) was injected intra-arterially $(50 \mu \mathrm{L})$ while the hypercapnia was achieved by bubbling the perfusate with $7 \%$ and $10 \% \mathrm{CO}_{2}$ (balanced in $\mathrm{O}_{2}$ ) for $5 \mathrm{~min}$. The diving reflex was also tested by topical administration of cold Ringer's solution $(0.5 \mathrm{~mL})$ into the animal's snout (Kawakami et al., 1967; Khurana et al., 1980). This reflex was evaluated to verify the integrity of a sympathoexcitatory reflex that is stimulated independently on the activation of central and peripheral chemoreceptors. The tests were performed randomly with a time interval of at least 10 min between consecutive stimuli.

\section{Tyrosine hydroxylase immunohistochemistry}

Adult animals were deeply anesthetized (2,2,2tribromoetanol, $250 \mathrm{mg} / \mathrm{kg}$, ip,Sigma- Aldrich, St Louis, EUA) at the end of experiments and perfused through the heart with phosphate buffer saline (PBS $0.1 \mathrm{M}, \mathrm{pH}$ 7.4 ), followed by $4 \%$ paraformaldehyde in phosphate buffer (PB $0.1 \mathrm{M}$ ). The in situ preparations were perfused only with $4 \%$ paraformaldehyde in PB $(0.1 \mathrm{M})$ at the end of experiments (after electrical noise detection). After fixation, the brainstems were then carefully removed and stored in the same fixative at $4{ }^{\circ} \mathrm{C}$ for $4 \mathrm{~h}$ and thereafter kept in $30 \%$ sucrose solution dissolved in $0.1 \mathrm{MPB}, \mathrm{pH} 7.4$, at $4{ }^{\circ} \mathrm{C}$ for $48 \mathrm{~h}$. The tissue was then placed in 2-methylbutane (SigmaAldrich, St Louis, EUA), frozen in dry ice (1 min), embedded in Tissue Tek OCT and cut in the cryostat (Leica CM 1850) at $25 \mu \mathrm{m}$. The brain slices were submitted to tyrosine hydroxylase $(\mathrm{TH})$ immunostaining to verify the effectiveness of the lesions of noradrenergic neurons in the A5 areas. To this, the coronal sections were incubated with polyclonal primary mouse antibody anti-TH (1:10000, Sigma-Aldrich) for $48 \mathrm{~h}$, and then incubated with biotinylated secondary rabbit antibody (1:1000, Vector Laboratories, Burlingame, CA, USA) for $1 \mathrm{~h}$. The biotinylated antibody was complexed with avidin $\mathrm{DH}$-biotinylated horseradish peroxidase (Vector Laboratories, Burlingame, CA, USA, code $\mathrm{PK}-4001)$ and revealed with peroxidase substrate 3,3'-diaminobenzidine tetrahydrochloride (DAB, Sigma). The sections were placed on gelatinized slides, dried, dehydrated through graded concentrations of alcohol, cleared in xylene, and sealed with a coverslip for later examination.

The TH immunoreactive cells (TH-IR) were analyzed by bright-filed microscopy, and labeled neurons were registered with the use of an image analysis system (Zeiss KS 300). For quantification, A5 noradrenergic neurons were bilaterally counted over the entire length of this cell group $(9.50-11.05 \mathrm{~mm}$ caudal from Bregma, divided into five sections) and a total average value was obtained. The data obtained in each animal were pooled and an average value was calculated in each experimental group. Images were captured and analyses were carried out using a computerized image analysis system (NIH System, Image $\mathrm{J}$ developed at the U.S. National Institutes of Health and available on the Internet at http://www.rsb. info.nih.gov/nih-image/). TH-IR cells in each section were counted by setting a size range for cellular nuclei (in pixels) and a threshold level for staining intensity. Representative sections in control and experimental groups were acquired at the same level, with the aid of the Adobe Photoshop Image Analysis Program, version 6.0. The counting was repeated at least twice for each section analyzed, which ensured that the number of profiles obtained was similar.

\section{Statistical analyses}

The values are reported as mean \pm SEM. The effectiveness of the lesions was analyzed using Student's unpaired $t$ test. For in vivo experiments, $V_{E}$, $V_{T}, f R, M A P$ and $H R$ data were compared using repeated measurement two-way ANOVA. When interactions between the factors were observed, groups were compared using Bonferroni's post hoc test. The data obtained in the in situ preparations were compared using repeated measurement one-way ANOVA and Student's unpaired t test. The statistical analysis was carried out using SigmaStat (Systat Software, Point Richmond, CA. USA), considering $P<0.05$ as significantly different. Graphs were generated using Prism (GraphPad, La Jolla, USA). 


\section{RESULTS}

\section{Effectiveness of the noradrenergic neuron lesions in the A5 of adult and juvenile rats}

A5 noradrenergic neurons were identified as the group of $\mathrm{TH}$-positive cells in the ventral pons, located laterally to the rostral edge of the facial motor nucleus, in between the exit of the facial nerve and the superior olive, as previously described (Byrum and Guyenet, 1987; Taxini et al., 2011). At the same coronal level, we also identified the TH-positive cells of the Locus coeruleus (LC), at the dorsal pons, as demonstrated in the Fig. 1A. The microinjections of anti-SAP-D $\beta H$ in the A5 region (A5-lesioned group) reduced the number of noradrenergic neurons in adult (Fig. 1Bi, Bii) and juvenile rats (Fig. $1 \mathrm{Ci}$, Cii). In adult animals, the total average number of bilateral TH-positive neurons in the A5 region of control group was $24 \pm 1$ while in the A5-lesioned group was $11 \pm 1(P<0.05)$. In the juvenile rats, similar results were observed (24 \pm 1 vs. $8 \pm 1$ neurons/section, respectively control and A5-lesioned groups, $P<0.05$ ). Our data indicate that our procedures were effective to lesion $55-70 \%$ of noradrenergic neurons in the $\mathrm{A} 5$ area of both adult and juvenile rats.

\section{Baseline cardiovascular and ventilatory parameters in animals with lesions of A5 noradrenergic neurons}

At normoxic and normocapnic conditions, unanesthetized animals with chemical lesions of A5 noradrenergic neurons $(n=9)$ showed similar cardiovascular (MAP: $106 \pm 3$ vs $104 \pm 4 \mathrm{mmHg}$; HR: $315 \pm 11$ vs 338 $\pm 5 \mathrm{bpm}$, respectively control and A5-lesioned groups) and ventilatory parameters (fR: $90 \pm 4$ vs $91 \pm 7$ breaths. $\min ^{-1}$; $\mathrm{V}_{\mathrm{T}}$ : $5.0 \pm 0.3$ vs $4.6 \pm 0.3 \mathrm{~mL} . \mathrm{kg}^{-1} ; \mathrm{V}_{\mathrm{E}}$ : $458 \pm 31$ vs $459 \pm 83 \mathrm{~mL} \cdot \mathrm{kg}^{-1} \cdot \mathrm{min}^{-1}$, respectively control and A5-lesioned groups) in comparison to control group $(n=8)$. The group data are shown in Fig. 2. Similar to unanesthetized animals, the in situ preparations of control $(n=7)$ and A5-lesioned juvenile rats $(n=6)$ exhibited similar values of $\mathrm{PN}$ burst amplitude $(41 \pm 10$ vs $45 \pm 20 \mu \mathrm{V}$, respectively control and A5-lesioned groups) and frequency $(13 \pm 1$ vs 15 $\pm 2 \mathrm{bpm}$ respectively control and A5-lesioned groups), and mean tSN levels $(12 \pm 2$ vs $13 \pm 2 \mu \mathrm{V}$, respectively control and A5-lesioned groups, Fig. 3A, 3D), as illustrated in Fig. 3. Regarding the sympathetic discharge pattern, $\mathrm{tSN}$ of control rats showed respiratory-related bursts with a ramping pattern that initiated during the inspiratory phase and reached a peak during the late part of inspiration or the beginning of post-I. This respiratory-modulated tSN peak was followed by a decline during the post-inspiratory phase, with lower levels during the E2 phase (Fig. 3A). A similar tSN discharge pattern was verified in the in situ preparations of A5-lesioned rats (Fig. 3A). The average values of normalized tSN during inspiration ( $54 \pm 6$ vs $63 \pm 5 \%$, respectively control and A5-lesioned groups), post-I ( $47 \pm 4$ vs $48 \pm 4 \%$, respectively control and A5lesioned groups) and E2 phases ( $37 \pm 4$ vs $43 \pm 3 \%$, respectively control and A5-lesioned groups) were similar between control and A5-lesioned groups respectively (Fig. 3E).

\section{Cardiovascular and respiratory reflex responses to hypoxia in unanesthetized A5-lesioned rats}

During hypoxic challenge $\left(7 \% \mathrm{O}_{2}\right.$ during $\left.30 \mathrm{~min}\right)$, the values of MAP (at $10 \mathrm{~min}: 103 \pm 4$ vs $104 \pm 9$; at $30 \mathrm{~min}$ : $97 \pm 2$ vs $101 \pm 4 \mathrm{mmHg}$; respectively control and A5-lesioned groups, Fig. 4A) and HR (at $10 \mathrm{~min}$ : $305 \pm 32$ vs $337 \pm 15$; at 30 min: $348 \pm 28$ vs 397 \pm 19 bpm; respectively control and A5-lesioned groups, Fig. 4B) were similar between control $(n=4)$ and A5lesioned group $(n=4)$. The exposure to hypoxia, at 10 and $30 \mathrm{~min}$, also elevated $V_{E}$ in control group due to increases in $\mathrm{fR}$ and $\mathrm{V}_{\mathrm{T}}(P<0.05$, Fig. $4 \mathrm{C}-\mathrm{E})$. In the A5lesioned rats, the hypoxic-induced increase in $V_{E}$, at 10 and 30 min during exposure, was mostly dependent upon an increase in $\mathrm{fR}(P<0.05$, Fig. $4 \mathrm{C}-\mathrm{E})$. In spite of the differences in the pattern of the ventilatory response to hypoxia, the average magnitudes of $\mathrm{fR}$ (at $10 \mathrm{~min}: 113 \pm 9$ vs $125 \pm 21$; at $30 \mathrm{~min}: 126 \pm 11$ vs $123 \pm 12$ breaths. $\mathrm{min}^{-1}$; respectively control and A5lesioned groups, Fig. 4C), $\mathrm{V}_{\mathrm{T}}$ (at $10 \mathrm{~min}: 7 \pm 0.6$ vs 6 \pm 1 ; at $30 \mathrm{~min}: 8 \pm 0.6$ vs $6 \pm 1 \mathrm{~mL} \cdot \mathrm{kg}^{-1}$; respectively control and A5-lesioned groups, Fig. 4D) and $V_{E}$ (at $10 \mathrm{~min}: 802 \pm 93$ vs $737 \pm 120$; at $30 \mathrm{~min}: 1028 \pm 131$ vs $761 \pm 93 \mathrm{~mL} \cdot \mathrm{min}^{-1} \cdot \mathrm{kg}^{-1}$; respectively control and A5-lesioned groups, Fig. 4E) were comparable between control $(n=8)$ and A5-lesioned $(n=4)$ rats.

\section{Sympathetic and phrenic responses to peripheral chemoreceptor activation in the in situ preparations of A5-lesioned rats}

Activation of the peripheral chemoreceptors with $\mathrm{KCN}$ promoted marked increases in the $\mathrm{tSN}$ activity as well as in the PN burst frequency and amplitude of control in situ preparations $(n=7 ; P<0.05)$, as demonstrated on Fig. 5. In juvenile rats with lesions of A5 noradrenergic neurons $(n=6)$, the magnitude of sympathoexcitatory response was attenuated in comparison to the control group (110 \pm 12 vs $58 \pm 8 \%$, $P<0.01$, respectively control and A5-lesioned groups, Fig. 5B). On the other hand, the magnitude of the increase in PN burst amplitude (20 \pm 4 vs $17 \pm 4 \%$, respectively control and A5-lesioned groups, Fig. 5C) and frequency $(20 \pm 3$ vs $21 \pm 2 \mathrm{cpm}$, respectively control and A5-lesioned groups, Fig. 5D) was similar between control and A5-lesioned groups.

\section{Cardiovascular and respiratory reflex responses to hypercapnia in unanesthetized A5-lesioned rats}

The exposure to hypercapnia $\left(7 \% \mathrm{CO}_{2}, 30 \mathrm{~min}\right)$ did not elicit changes in MAP and HR of both experimental groups. Moreover, the values of MAP (at $10 \mathrm{~min}$ : 102 \pm 2 vs $105 \pm 6$; at $30 \mathrm{~min}: 100 \pm 1$ vs $105 \pm 6 \mathrm{mmHg}$ ) and HR (at $10 \mathrm{~min}$ : $285 \pm 13$ vs $317 \pm 27$; at $30 \mathrm{~min}$ : $302 \pm 9$ vs $301 \pm 22$ bpm) were similar between control $(n=4)$ and A5-lesioned groups $(n=5)$, as illustrated in Fig. 6A, B. Regarding the respiratory changes elicited by 
A

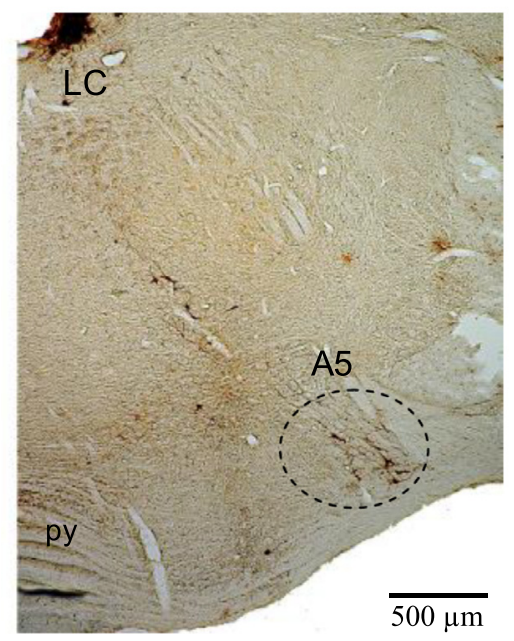

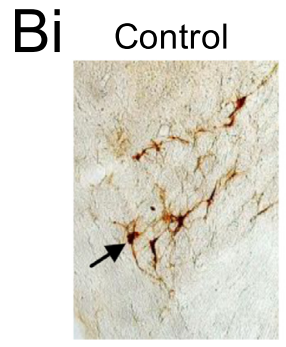

Ci Control

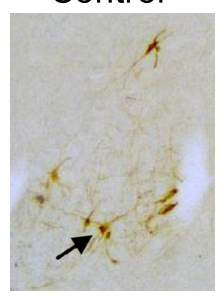

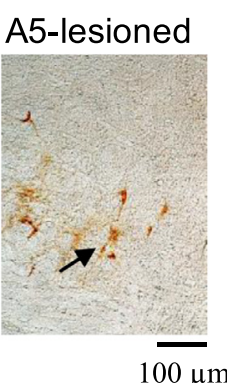

A5-lesioned

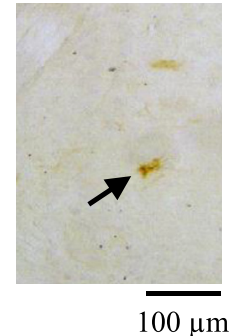

Bii

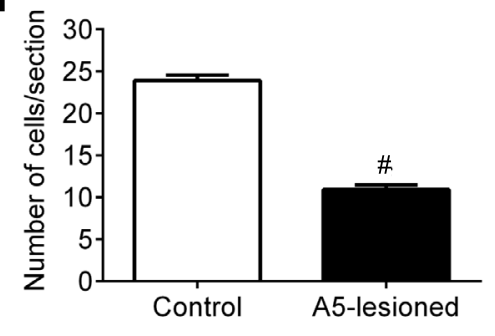

Cii

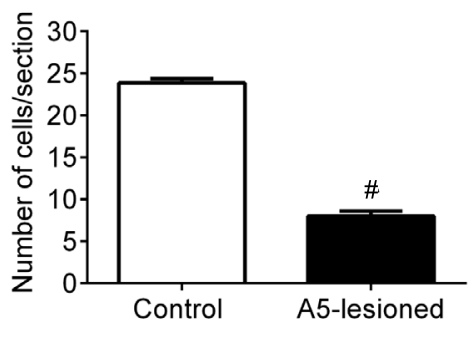

Fig. 1. Immunohistochemical identification of A5 tyrosine hydroxylase (TH) immunoreactive neurons. Panel A: coronal section of a rat illustrating the TH-positive cells in the ventrolateral pons, corresponding to the A5 area (dotted line). In this section, also note a great density of TH-positive cells at the dorsal pons, adjacent to the fourth ventricle, in the Locus Coeruleus (LC). Panel Bi: TH-immunoreactive neurons in the A5 region of adult rats, representative of their respective groups, which received either IgG-SAP (control) or anti-D $\beta \mathrm{H}-\mathrm{SAP}$ microinjections (A5-lesioned) seven days prior to the experiments in vivo. The arrows indicate TH neurons in the A5 region. Panel Bii: average number of TH-positive neurons in the A5 area of adult control $(n=13)$ and A5-lesioned rats $(n=13)$. Panel Ci: TH-immunoreactive neurons in the A5 region of juvenile rats, representative of their respective groups, which received either IgG-SAP (control) or anti-D $\beta H$-SAP microinjections (A5-lesioned) seven days prior to the in situ experiments. The arrows indicate TH neurons in the A5 region. Panel Cii: average number of TH-positive neurons in the A5 area of control $(n=7)$ and A5-lesioned in situ preparations $(n=6)$. Abbreviation: py, pyramid. "Different from respective control group $(P<0.05)$.
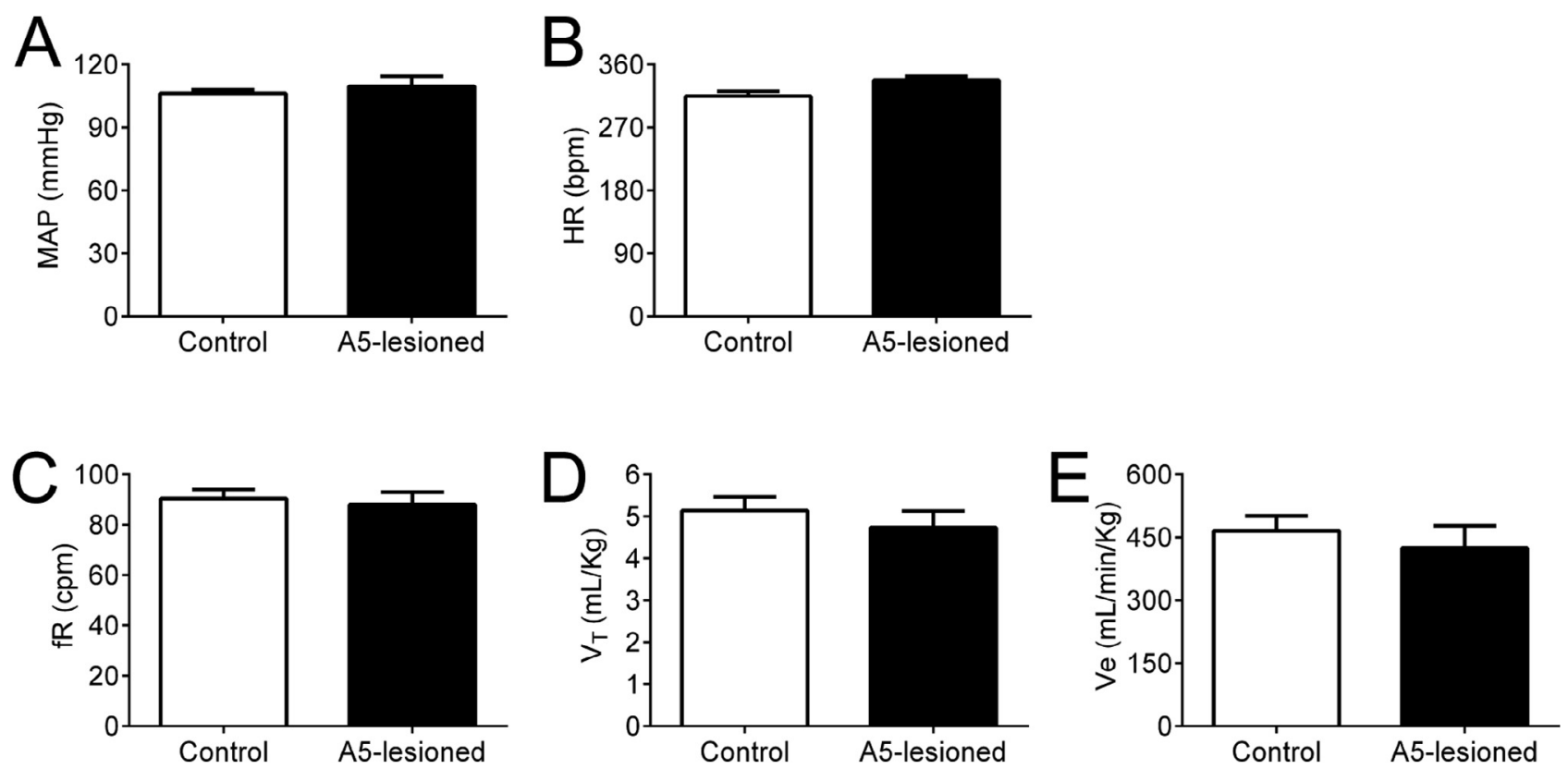

Fig. 2. Baseline cardiorespiratory parameters in unanesthetized adult rats with lesions of TH-positive neurons in the A5 area. Average values of mean arterial pressure (MAP, panel $A)$, heart rate $(H R$, panel $B)$, respiratory frequency ( $f R$, panel $C)$, tidal volume $\left(V_{T}\right.$, panel $\left.D\right)$ and minute ventilation $\left(\mathrm{V}_{\mathrm{E}}\right.$, panel $\left.\mathrm{E}\right)$ of adult rats from control $(n=8)$ and from A5-lesioned groups $(n=9)$.

hypercapnia, both experimental groups showed significant increases in $\mathrm{fR}, \mathrm{V}_{\mathrm{T}}$ and $\mathrm{V}_{\mathrm{E}}$ at 10 and $30 \mathrm{~min}$ in both groups $(P<0.001$, Fig. $6 \mathrm{C}-\mathrm{E})$. The magnitude of reflex increases in fR (at $10 \mathrm{~min}: 128 \pm 14$ vs 140 \pm 17 ; at $30 \mathrm{~min}: 138 \pm 5$ vs $149 \pm 13$ breaths $\min ^{-1}$; respectively control and A5-lesioned groups, Fig. 6C), 

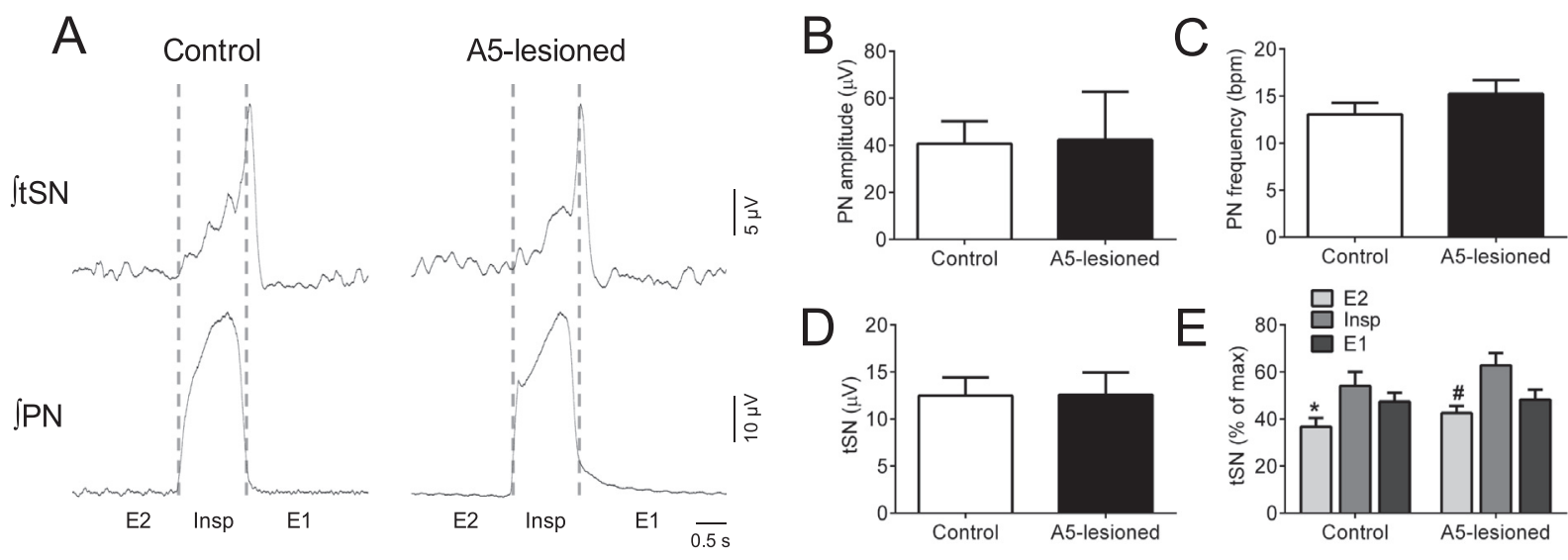

Fig. 3. Baseline phrenic and sympathetic nerve activities of in situ preparations of rats with lesions of TH-positive neurons in the A5 area. Panel A: cycle-triggered averages (3-min epochs) of integrated $(\delta$ ) phrenic $(\mathrm{PN})$ and sympathetic nerve (tSN) activities of control and A5-lesioned in situ preparations, representative from their groups. Panels B-D: average values of phrenic burst amplitude and frequency, and mean thoracic sympathetic activity, respectively, of control $(n=7)$ and A5-lesioned groups $(n=6)$. Panel E: percentage values of tSN activity during inspiration (insp), first (E1) and second stage of expiration (E2) in control $(n=7)$ and A5-lesioned in situ preparations $(n=6)$. "Different from control inspiratory phase. \# Different from A5-lesioned inspiratory phase.

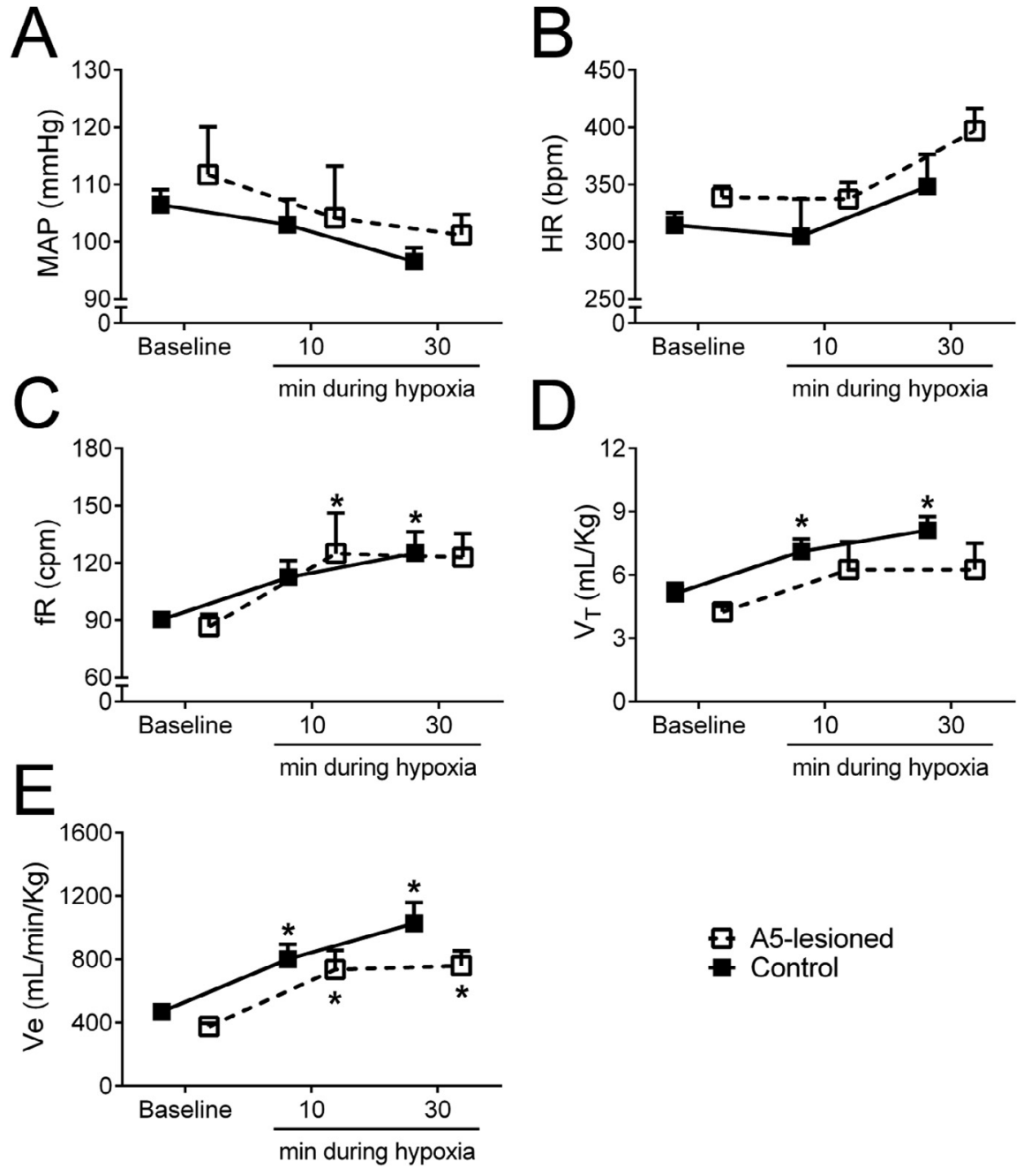

Fig. 4. Hypoxia-induced cardiorespiratory reflex responses in adult rats with lesions of the A5 THpositive neurons. Average values of mean arterial pressure (MAP, panel A), heart rate (HR, panel $B)$, respiratory frequency $(f R$, panel $C)$, tidal volume $\left(V_{T}\right.$, panel $\left.D\right)$ and minute ventilation $\left(V_{E}\right.$, panel E) of adult rats from control $(n=8)$ and from A5-lesioned groups $(n=4)$, before (baseline) and during the exposure to hypoxia $\left(7 \% \mathrm{O}_{2}\right)$ for $30 \mathrm{~min}$. "Different from respective baseline.
$V_{T}$ (at 10 min: $8 \pm 0.4$ vs $7 \pm 1$; at 30 min: $9 \pm 0.5$ vs $8 \pm 1 \mathrm{~mL} \mathrm{~kg}^{-1}$; respectively control and $\mathrm{A} 5$-lesioned groups, Fig. 6D) and $V_{E}$ (at $10 \mathrm{~min}$ : $1011 \pm 65$ vs $1087 \pm 256$; at $30 \mathrm{~min}: \quad 1297 \pm 95$ vs 1204 $\pm 226 \mathrm{~mL} \mathrm{~kg}{ }^{-1} \mathrm{~min}^{-1}$; respectively control and A5-lesioned groups, Fig. 6E), was similar between control $(n=8)$ and A5-lesioned group $(n=5)$.

\section{Sympathetic and phrenic} responses to hypercapnia in the in situ preparations of A5-lesioned rats

The rise in the fractional concentration of $\mathrm{CO}_{2}$ in the perfusate of in situ preparations $(7 \%$ and $10 \% \mathrm{CO}_{2}$ ) increased the $\mathrm{tSN}$ and $\mathrm{PN}$ activities in control $(n=7)$ and A5-lesioned groups $(n=6)$, as illustrated in Fig. 7. The tSN response to $7 \% \mathrm{CO}_{2}$ was attenuated in A5-lesioned rats compared to controls $(10 \pm 1$ vs $4 \pm 2 \%$, $P<0.05$, Fig. 7Bi); however, at $10 \%$ $\mathrm{CO}_{2}$, the magnitude of $\mathrm{tSN}$ response was similar between groups ( $16 \pm 3$ vs $11 \pm 2 \%$ ). The increase in PN burst amplitude in response to $7 \%$ $\mathrm{CO}_{2}(8 \pm 4$ vs $7 \pm 2 \%$, Fig. $7 \mathrm{Bi})$ and $10 \% \quad \mathrm{CO}_{2} \quad(15 \pm 4$ vs $20 \pm 4 \%$, Fig. 7Cii) were similar between control $(n=7)$ and A5-lesioned group $(n=6)$. No significant changes were observed in the PN burst frequency in response to the two levels of $\mathrm{CO}_{2}$ in both 
A

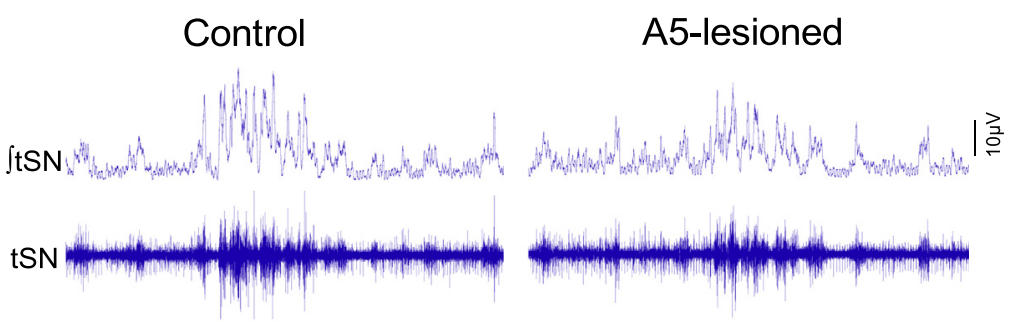

$\int_{\operatorname{PN}} / 11+1$
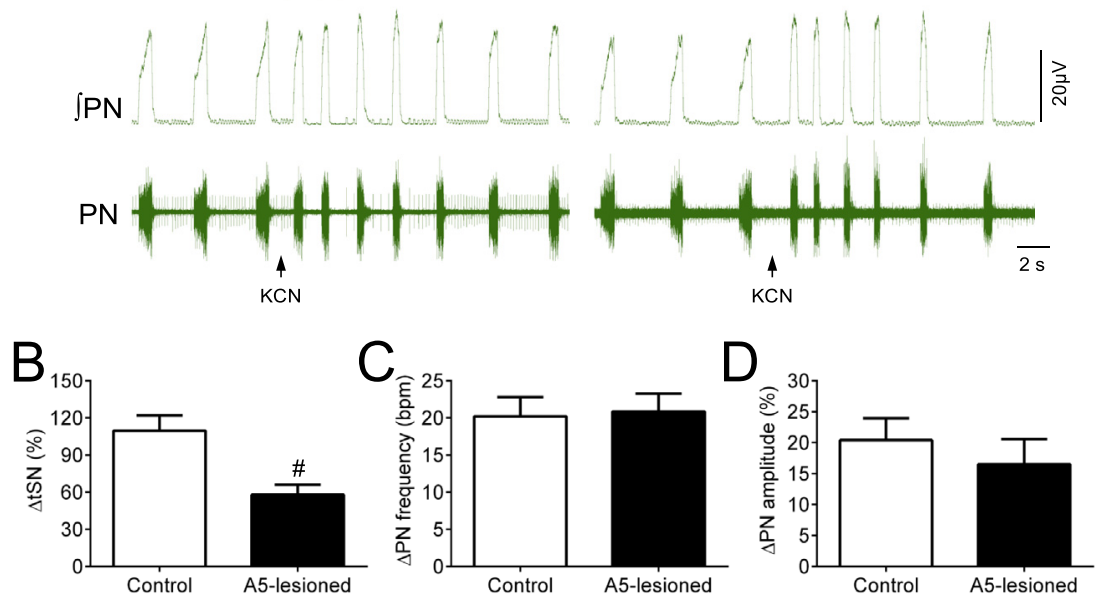

Fig. 5. Sympathetic and phrenic reflex responses to stimulation of peripheral chemoreceptors in the in situ preparations of rats with lesions of the A5 TH-positive neurons. Panel A: raw and integrated $\left(\int\right)$ recordings of thoracic sympathetic (tSN) and phrenic (PN) activities, illustrating the sympathetic and phrenic changes elicited by peripheral chemoreceptor stimulation with potassium cyanide (KCN, arrow) in a control and A5-lesioned in situ preparation. Panels B-D: KCN-induced changes $(\Delta)$ in the tSN activity and in the PN frequency and amplitude, respectively, of in situ preparations from control $(n=7)$ and A5-lesioned groups $(n=6)$. "Different from control group.

experimental groups ( $\triangle \mathrm{PN}$ frequency $-7 \% \mathrm{CO}_{2}: 1 \pm 1 \mathrm{vs}$ $1 \pm 1 \mathrm{cpm} ; 10 \% \mathrm{CO}_{2}: 1 \pm 1$ vs $0 \pm 1 \mathrm{cpm}$; respectively control and A5-lesioned animals).

\section{Diving reflex responses in A5-lesioned rats}

The activation of the diving reflex evoked responses of sympatho-excitation $(75 \pm 14$ vs $60 \pm 14 \%$, respectively control and A5-lesioned rats, $P<0.01$ ) and expiratory time lengthening $(2 \pm 0.4$ vs $2 \pm 0.7 \mathrm{~s}$, respectively control and A5-lesioned rats, $P<0.01)$ of similar magnitude in control $(n=7)$ and A5-lesioned in situ preparations $(n=6)$.

\section{DISCUSSION}

In the present study, we report that lesions of A5 noradrenergic cells did not modify resting arterial pressure and minute ventilation of unanesthetized rats. In agreement with these findings, we also show that baseline sympathetic and phrenic activities, as well as the respiratory-sympathetic coupling pattern, were not altered in the in situ preparations of A5-lesioned rats. On the other hand, we found that A5 noradrenergic neuron lesion depressed the sympatho-excitation, but not ventilatory response, elicited by hypoxia and, to a less extent, hypercapnia. Our findings support the notion that the maintenance of resting sympathetic vasomotor tonus and respiratory rhythm of rats, at least in juvenile/adult ages, does not require the noradrenergic neurons of the A5 area. In contrast, A5 cells contribute to the complete expression of sympathetic chemoreflex response in unanesthetized conditions.

\section{Contribution of A5 noradrenergic neurons to the maintenance of baseline arterial pressure and respiratory rhythm}

Anatomical and electrophysiological evidence demonstrates that the A5 noradrenergic neurons that exhibit low activity at rest, are inhibited during baroreflex activation (Huangfu et al., 1991; Kanbar et al., 2011), interact with cardiorespiratory centers of the medulla oblongata and spinal cord (Loewy et al., 1979b; Byrum and Guyenet, 1987; Huangfu et al., 1991), and evoke a robust sympathoexcitatory response when stimulated (Kanbar et al., 2011). These observations suggest that A5 neurons are an important excitatory component of sympathetic nervous system. However, acute pharmacological inhibition and chronic lesion of noradrenergic cells in the A5 did not reduce baseline arterial pressure levels (Koshiya and Guyenet, 1994a; Schreihofer and Guyenet, 2000; Taxini et al., 2011). It is important to mention that all these previous studies were performed on anesthetized rats - an experimental condition that may interfere with the normal functioning of sympathetic nervous system (Machado and Bonagamba, 1992; Accorsi-Mendonca et al., 2007; Massey et al., 2015). In this regard, we demonstrated that lesions of the noradrenergic neurons in the A5 did not alter baseline arterial pressure of conscious rats and the sympathetic activity levels of unanesthetized in situ rat preparations. The arterially perfused, decerebrated in situ preparations may also represent a technical limitation; however, data from literature support that the functioning of brainstem network, the pattern of sympathetic discharge and vasomotor control mechanisms in the in situ preparations resemble to the mechanisms in vivo (Zoccal et al., 2009; McBryde et al., 2013; Moraes et al., 2013). Therefore, our results agree with previous observations, and support the concept that A5 noradrenergic neurons do not contribute to the maintenance of baseline sympathetic activity in unanesthetized conditions.

In addition to its tonic nature, the sympathetic activity displays oscillatory components that are important for the control of vascular tonus (Barman and Gebber, 2000; Simms et al., 2009). Part of the sympathetic rhythmicity is entrained with the breathing cycle and depends on inputs from respiratory network to premotor sympathetic neurons (Malpas, 1998; Molkov et al., 2011; Moraes 


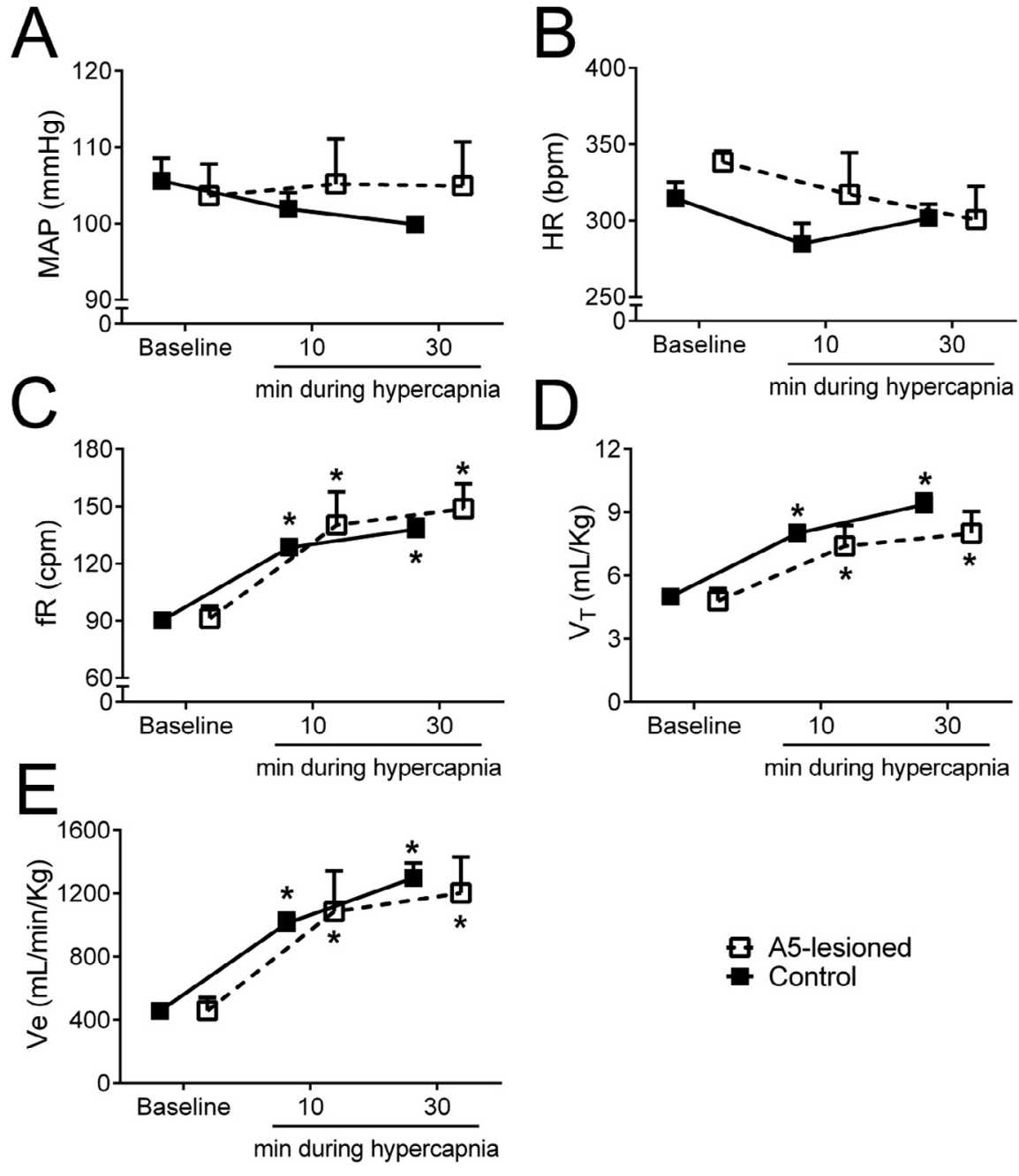

Fig. 6. Hypercapnia-induced cardiorespiratory reflex responses in adult rats with lesions of the $A 5$ $\mathrm{TH}$-positive neurons. Average values of mean arterial pressure (MAP, panel A), heart rate (HR, panel $B)$, respiratory frequency $(f R$, panel $C)$, tidal volume $\left(V_{T}\right.$, panel $\left.D\right)$ and minute ventilation $\left(V_{E}\right.$, panel E) of adult rats from control $(n=8)$ and from A5-lesioned groups $(n=5)$, before (baseline) and during the exposure to hypercapnia $\left(7 \% \mathrm{CO}_{2}\right)$ for $30 \mathrm{~min}$. "Different from respective baseline.

et al., 2013). Previous studies demonstrated that the pons critically contributes to the generation of respiratorysympathetic coupling, since the pontine-medullary disconnection abolished the sympathetic oscillations entrained with respiration (Baekey et al., 2008). By the fact that the A5 cells received projections from ventral respiratory group (Guyenet et al., 1993; Rosin et al., 2006) and some of the A5 neurons exhibit respiratory-related pattern of discharge (Guyenet et al., 1993), this region could potentially contribute to the generation of rhythmical respiratory oscillations in the sympathetic outflow. However, we found that lesion of A5 neurons did not alter the baseline pattern of respiratory modulation of sympathetic activity of the in situ preparations, indicating other neurons in the pons than the A5 noradrenergic neurons contribute to the rhythmical control of sympathetic activity to the cardiovascular system.

With respect to the respiratory activity, previous studies suggest the existence of descending projections from the A5 area to the ventromedullary respiratory network (Dobbins and Feldman, 1994). In neonates, it has been shown that A5 noradrenergic neurons tonically inhibit the ventromedullary respiratory neurons and reduce the $f_{R}$ (Viemari and Hilaire, 2003; Hilaire et al., 2004; Viemari et al., 2004a). In contrast, we found that baseline ventilation of adult unanesthetized rats and the phrenic activity of in situ preparations of juvenile rats were similar between control and A5-lesioned groups. Our findings agree with previous suggestion that the strength of the A5-dependent inhibitory effect on $f_{R}$ may be age dependent (Hilaire et al., 2004), and indicate that A5 noradrenergic neurons do not play a role in the generation of respiratory rhythm in juvenile/adult animals.

\section{A5 noradrenergic neurons and the autonomic and respiratory responses to hypoxia and hypercapnia}

In our experimental conditions, we found that the increase in ventilation during hypoxia and hypercapnia in A5-lesioned unanesthetized rats was similar to control rats. Moreover, the values of arterial pressure during hypoxia and hypercapnia were similar between control and A5lesioned rats. However, during prolonged hypoxia or hypercapnia exposure in vivo, a prominent response of vasodilatation is also observed in conjunction to the sympatho-excitatory response, which affects the evaluation of sympathetic-mediated pressor response (Barros et al., 2002). For that reason, the experiments with in situ preparations were important to perform direct measurements of the chemoreflex control of sympathetic activity in the absence of anesthesia. In these experiments, while central chemoreceptors were activated using a perfusate with elevated levels of $\mathrm{CO}_{2}$, the peripheral chemoreceptors were activated with $\mathrm{KCN}$ in order to produce consistent respiratory and sympathetic reflex responses among preparations (Lemes et al., 2016).

Similar to the in vivo data, the phrenic responses to $\mathrm{KCN}$ and hypercapnia were similar between in situ preparation of control and A5-lesioned rats, indicating that A5 noradrenergic neurons do not contribute to the processing of chemoreflex ventilatory responses. On the other hand, the sympatho-excitation elicited by peripheral chemoreceptor stimulation and hypercapnia in situ was significantly depressed in A5-lesioned rats. Importantly, the sympathetic response to stimulation of diving reflex was not affected in A5-lesioned rats, 

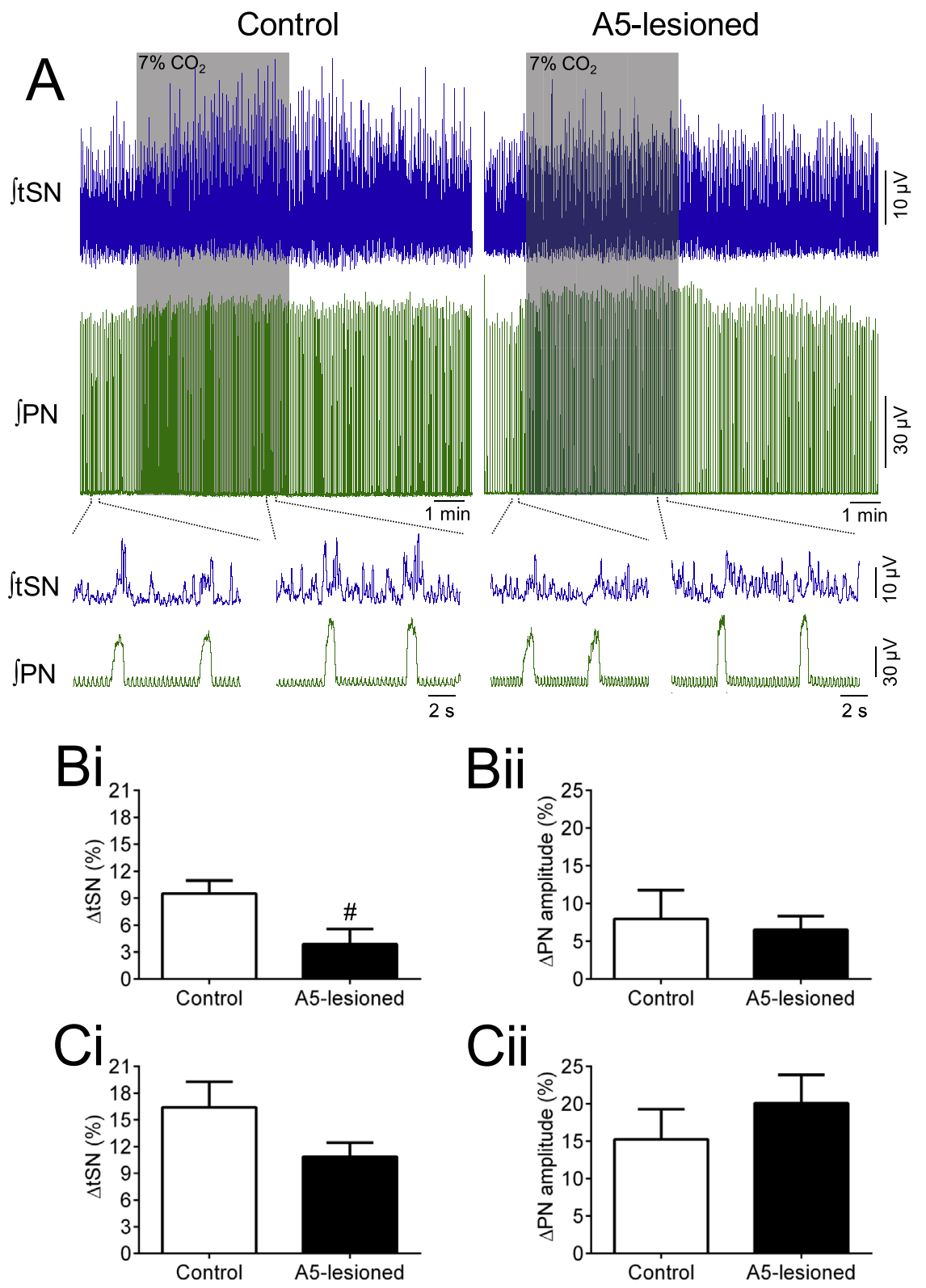

Fig. 7. Sympathetic and phrenic reflex responses of in situ preparations of rats with lesions of the A5 TH-positive neurons exposed to hypercapnia. Panel A: integrated $\left(\int\right)$ recordings of thoracic sympathetic (tSN) and phrenic (PN) activities, illustrating the sympathetic and phrenic changes elicited by hypercapnia $\left(7 \% \mathrm{CO}_{2}\right.$, shaded area) in a control and A5-lesioned in situ preparation. Panels $\mathrm{Bi}$ and Bii: Reflex changes $(\Delta)$ in the tSN activity and in the PN amplitude, respectively, of in situ preparations from control $(n=7)$ and A5-lesioned groups $(n=6)$ exposed to $7 \% \mathrm{CO}_{2}$ Panels $\mathrm{Ci}$ and Cii: Reflex changes $(\Delta)$ in the tSN activity and in the PN amplitude, respectively, of in situ preparations from control $(n=7)$ and A5-lesioned groups $(n=6)$ exposed to $10 \% \mathrm{CO}_{2}$. "Different from control group.

suggesting that the processing of other sympathoexcitatory reflexes was preserved. Our data, therefore, indicate that the A5 noradrenergic neurons are recruited during chemoreflex activation and contribute mostly to the sympatho-excitatory response in anesthetic-free conditions. On the base of anatomical evidence (Byrum and Guyenet, 1987), we hypothesize that synapses from the NTS neurons that receive peripheral chemoreceptor inputs stimulate the A5 neurons in conditions of hypoxia. Moreover, by the fact that A5 noradrenergic neurons dis- play reduced sensitivity to $\mathrm{pH}$ in vitro (Kanbar et al., 2011), we consider that the activation of A5 neurons during hypercapnia, and the generation of sympatho-excitatory reflex response, may depend on excitatory inputs from $\mathrm{CO}_{2}$-sensitive regions that are connected to $A 5$, such as retrotrapezoid nucleus (RTN) and nucleus tractus solitarii (NTS) (Ritucci et al., 1997; Rosin et al., 2006). Koshiya and Guyenet (1994b) described that intrathecal administration of $\alpha$ - or $\beta$ adrenergic antagonists did not affect the magnitude of sympathoexcitatory response to peripheral chemoreflex stimulation, at least in anesthetized conditions. These observations raise the possibility that the contribution of A5 neurons to the chemoreflex sympathetic response may rely on either the release of non-catecholaminergic fast-acting transmitter at the level of IML, similarly to C1 neurons (Holloway et al., 2013; Abbott et al., 2014), or the activation of pre-sympathetic neurons of the RVLM (Byrum and Guyenet, 1987). Both possibilities require additional experiments to be elucidated.

\section{CONCLUSIONS}

In conclusion, we demonstrated that A5 noradrenergic neurons do not play a relevant role in the maintenance of baseline sympathetic vasomotor tonus and $f_{R}$ as well as in the processing of phrenic response to hypoxia and hypercapnia. In contrast, A5 noradrenergic cells contribute to the emergence of sympathetic response to hypoxia and hypercapnia in experimental conditions free of the depressant effects of anesthesia. Our data, therefore, support the notion that A5 noradrenergic neurons are an important component of the sympathetic nervous system, recruited mainly during conditions of metabolic challenges.

\section{Perspectives}

Based upon the evidence that A5 neurons are activated during hypoxia and hypercapnia, and by the fact that brainstem noradrenergic neurons are an important component of wake-promoting system and contribute to increase sympathetic tone upon awakening ( $\mathrm{Li}$ and Nattie, 2006; Burke et al., 2015; Bellesi et al., 2016), additional experiments will be important to investigate the 
involvement of A5 noradrenergic cells in the arousal responses linked to chemoreflex activation. Moreover, previous studies have evidenced that severe loss of A5 neurons in the $\mathrm{A} 5$ area contributes to the manifestation of autonomic disorder associated with the neurodegenerative disease of multiple system atrophy (Benarroch et al., 2008). These observations open the possibility that changes in the functioning of $A 5$ neurons may underpin the development of augmented sympathetic levels, especially in pathological conditions associated with hyperactivity of peripheral chemoreceptors, such as obstructive sleep apnea (Narkiewicz et al., 1998), heart failure (Toledo et al., 2017) and neurogenic hypertension (Pijacka et al., 2016).

\section{CONFLICT OF INTERESTS}

Nothing to disclose.

\section{AUTHOR CONTRIBUTION}

CLT, TSM, ACT, KB, LHG and DBZ designed the research. CLT, LHG and DBZ performed the experiments, analyzed and interpreted the data. All authors provided critical and intellectual inputs during the preparation of the manuscript and approved the final version.

Acknowledgments-This work was funded by the São Paulo Research Foundation (FAPESP; grant number 2013/06077-5 and 2013/17251-6) and the National Institutes of Health (NIH, grant number R01 AT008632).

\section{REFERENCES}

Abbott SB, Holloway BB, Viar KE, Guyenet PG (2014) Vesicular glutamate transporter 2 is required for the respiratory and parasympathetic activation produced by optogenetic stimulation of catecholaminergic neurons in the rostral ventrolateral medulla of mice in vivo. Eur J Neurosci 39:98-106.

Accorsi-Mendonca D, Leao RM, Aguiar JF, Varanda WA, Machado $\mathrm{BH}$ (2007) Urethane inhibits the GABAergic neurotransmission in the nucleus of the solitary tract of rat brain stem slices. Am J Physiol Regul Integr Comp Physiol 292:R396-R402.

Baekey DM, Dick TE, Paton JF (2008) Pontomedullary transection attenuates central respiratory modulation of sympathetic discharge, heart rate and the baroreceptor reflex in the in situ rat preparation. Exp Physiol 93:803-816.

Barman SM, Gebber GL (2000) "Rapid" rhythmic discharges of sympathetic nerves: sources, mechanisms of generation, and physiological relevance. J Biol Rhythms 15:365-379.

Barros RCH, Bonagamba LGH, Okamoto-Canesin R, de Oliveira M, Branco LGS, Machado BH (2002) Cardiovascular responses to chemoreflex activation with potassium cyanide or hypoxic hypoxia in awake rats. Auton Neurosci 97:110-115.

Bartlett Jr D, Tenney SM (1970) Control of breathing in experimental anemia. Respir Physiol 10:384-395.

Bellesi M, Tononi G, Cirelli C, Serra PA (2016) Region-specific dissociation between cortical noradrenaline levels and the sleep/ wake cycle. Sleep 39:143-154.

Benarroch EE, Schmeichel AM, Low PA, Sandroni P, Parisi JE (2008) Loss of A5 noradrenergic neurons in multiple system atrophy. Acta Neuropathol 115:629-634.

Bezin L, Marcel D, Debure LI, Ginovart N, Rousset C, Pujol JF, Weissmann D (1994) Postnatal development of the tyrosine hydroxylase-containing cell population within the rat locus coeruleus: topological organization and phenotypic plasticity. $J$ Neurosci 14:7486-7501.

Biancardi V, Bicego KC, Almeida MC, Gargaglioni LH (2008) Locus coeruleus noradrenergic neurons and $\mathrm{CO} 2$ drive to breathing. Pflugers Arch 455:1119-1128.

Burke PG, Kanbar R, Viar KE, Stornetta RL, Guyenet PG (2015) Selective optogenetic stimulation of the retrotrapezoid nucleus in sleeping rats activates breathing without changing blood pressure or causing arousal or sighs. J Appl Physiol 118:1491-1501.

Byrum CE, Guyenet PG (1987) Afferent and efferent connections of the A5 noradrenergic cell group in the rat. J Comp Neurol 261:529-542.

Costa-Silva JH, Zoccal DB, Machado BH (2010) Glutamatergic antagonism in the NTS decreases post-inspiratory drive and changes phrenic and sympathetic coupling during chemoreflex activation. J Neurophysiol 103:2095-2106.

Dawid-Milner MS, Lara JP, Gonzalez-Baron S, Spyer KM (2001) Respiratory effects of stimulation of cell bodies of the A5 region in the anaesthetised rat. Pflugers Arch 441:434-443.

Dobbins EG, Feldman JL (1994) Brainstem network controlling descending drive to phrenic motoneurons in rat. J Comp Neurol 347:64-86.

Doi A, Ramirez JM (2010) State-dependent interactions between excitatory neuromodulators in the neuronal control of breathing. $J$ Neurosci 30:8251-8262.

Guyenet PG, Koshiya N, Huangfu D, Verberne AJ, Riley TA (1993) Central respiratory control of $\mathrm{A} 5$ and $\mathrm{A} 6$ pontine noradrenergic neurons. Am J Physiol 264:R1035-R1044.

Hilaire G, Monteau R, Errchidi S (1989) Possible modulation of the medullary respiratory rhythm generator by the noradrenergic A5 area: an in vitro study in the newborn rat. Brain Res 485:325-332.

Hilaire G, Viemari JC, Coulon P, Simonneau M, Bevengut M (2004) Modulation of the respiratory rhythm generator by the pontine noradrenergic A5 and A6 groups in rodents. Respir Physiol Neurobiol 143:187-197.

Hirooka Y, Polson JW, Potts PD, Dampney RA (1997) Hypoxiainduced Fos expression in neurons projecting to the pressor region in the rostral ventrolateral medulla. Neuroscience 80:1209-1224.

Holloway BB, Stornetta RL, Bochorishvili G, Erisir A, Viar KE, Guyenet PG (2013) Monosynaptic glutamatergic activation of locus coeruleus and other lower brainstem noradrenergic neurons by the $\mathrm{C} 1$ cells in mice. J Neurosci 33:18792-18805.

Huangfu DH, Koshiya N, Guyenet PG (1991) A5 noradrenergic unit activity and sympathetic nerve discharge in rats. Am J Physiol 261:R393-R402.

Jodkowski JS, Coles SK, Dick TE (1997) Prolongation in expiration evoked from ventrolateral pons of adult rats. J Appl Physiol 82:377-381.

Jodkowski JS, Coles SK, Dick TE (1994) A 'pneumotaxic centre' in rats. Neurosci Lett 172:67-72.

Kanbar R, Depuy SD, West GH, Stornetta RL, Guyenet PG (2011) Regulation of visceral sympathetic tone by $\mathrm{A} 5$ noradrenergic neurons in rodents. J Physiol 589:903-917.

Kawakami Y, Natelson BH, DuBois AR (1967) Cardiovascular effects of face immersion and factors affecting diving reflex in man. J Appl Physiol 23:964-970.

Khurana RK, Watabiki S, Hebel JR, Toro R, Nelson E (1980) Cold face test in the assessment of trigeminal-brainstem-vagal function in humans. Ann Neurol 7:144-149.

Koshiya N, Guyenet PG (1994a) Role of the pons in the carotid sympathetic chemoreflex. Am J Physiol Regul Integr Comp Physiol 267:R508-R518.

Koshiya N, Guyenet PG (1994b) A5 noradrenergic neurons and the carotid sympathetic chemoreflex. Am J Physiol 267:R519-R526.

Kvetnansky R, Bodnar I, Shahar T, Uhereczky G, Krizanova O, Mravec B (2006) Effect of lesion of A5 and A7 brainstem noradrenergic areas or transection of brainstem pathways on sympathoadrenal activity in rats during immobilization stress. Neurochem Res 31:267-275.

Lagercrantz H, Pequignot JM, Hertzberg T, Holgert H, Ringstedt T (1994) Birth-related changes of expression and turnover of some 
neuroactive agents and respiratory control. Biol Neonate 65:145-148.

Lemes EV, Aiko S, Orbem CB, Formentin C, Bassi M, Colombari E, Zoccal DB (2016) Long-term facilitation of expiratory and sympathetic activities following acute intermittent hypoxia in rats. Acta Physiol (Oxf) 217:254-266.

Li A, Nattie E (2006) Catecholamine neurones in rats modulate sleep, breathing, central chemoreception and breathing variability. J Physiol 570:385-396.

Loewy AD, McKellar S, Saper CB (1979a) Direct projections from the A5 catecholamine cell group to the intermediolateral cell column. Brain Res 174:309-314.

Loewy AD, Gregorie EM, McKellar S, Baker RP (1979b) Electrophysiological evidence that the A5 catecholamine cell group is a vasomotor center. Brain Res 178:196-200.

Lopez Gonzalez MV, Diaz Casares MA, Peinado Aragones CA, Lara Munoz JP, Barbancho MA, Dawid-Milner MS (2013) Neurons of the A5 region are required for the tachycardia evoked by electrical stimulation of the hypothalamic defence area in anaesthetised rats. Exp Physiol 98:1279-1294.

Machado BH, Bonagamba LG (1992) Microinjection of L-glutamate into the nucleus tractus solitarii increases arterial pressure in conscious rats. Brain Res 576:131-138.

Madden CJ, Sved AF (2003) Cardiovascular regulation after destruction of the $\mathrm{C} 1$ cell group of the rostral ventrolateral medulla in rats. Am J Physiol Heart Circ Physiol 285: $\mathrm{H} 2734-\mathrm{H} 2748$.

Maiorov DN, Malpas SC, Head GA (2000) Influence of pontine A5 region on renal sympathetic nerve activity in conscious rabbits. Am J Physiol Regul Integr Comp Physiol 278:R311-R319.

Malpas SC (1998) The rhythmicity of sympathetic nerve activity. Prog Neurobiol 56:65-96.

Massey CA, Iceman KE, Johansen SL, Wu Y, Harris MB, Richerson GB (2015) Isoflurane abolishes spontaneous firing of serotonin neurons and masks their $\mathrm{pH} / \mathrm{CO}(2)$ chemosensitivity. J Neurophysiol 113:2879-2888.

McBryde FD, Abdala AP, Hendy EB, Pijacka W, Marvar P, Moraes DJ, Sobotka PA, Paton JF (2013) The carotid body as a putative therapeutic target for the treatment of neurogenic hypertension. Nature Commun 4:2395.

Molkov YI, Zoccal DB, Moraes DJ, Paton JF, Machado BH, Rybak IA (2011) Intermittent hypoxia-induced sensitization of central chemoreceptors contributes to sympathetic nerve activity during late expiration in rats. J Neurophysiol 105:3080-3091.

Moraes DJ, da Silva MP, Bonagamba LG, Mecawi AS, Zoccal DB, Antunes-Rodrigues J, Varanda WA, Machado BH (2013) Electrophysiological properties of rostral ventrolateral medulla presympathetic neurons modulated by the respiratory network in rats. J Neurosci 33:19223-19237.

Narkiewicz K, van de Borne PJH, Montano N, Dyken ME, Phillips BG, Somers VK (1998) Contribution of tonic chemoreflex activation to sympathetic activity and blood pressure in patients with obstructive sleep apnea. Circulation 97:943-945.

Neil JJ, Loewy AD (1982) Decreases in blood pressure in response to L-glutamate microinjections into the A5 catecholamine cell group. Brain Res 241:271-278.

Oliveira LM, Moreira TS, Kuo FS, Mulkey DK, Takakura AC (2016) Alpha1- and alpha2-adrenergic receptors in the retrotrapezoid nucleus differentially regulate breathing in anesthetized adult rats. J Neurophysiol 116:1036-1048.

Paton JF (1996) A working heart-brainstem preparation of the mouse. J Neurosci Methods 65:63-68.

Pijacka W, Moraes DJ, Ratcliffe LE, Nightingale AK, Hart EC, da Silva MP, Machado BH, McBryde FD, Abdala AP, Ford AP, Paton JF
(2016) Purinergic receptors in the carotid body as a new drug target for controlling hypertension. Nat Med 22:1151-1159.

Ritucci NA, Dean JB, Putnam RW (1997) Intracellular pH response to hypercapnia in neurons from chemosensitive areas of the medulla. Am J Physiol 273:R433-R441.

Rosin DL, Chang DA, Guyenet PG (2006) Afferent and efferent connections of the rat retrotrapezoid nucleus. J Comp Neurol 499:64-89.

Schreihofer AM, Guyenet PG (2000) Sympathetic reflexes after depletion of bulbospinal catecholaminergic neurons with antiDbetaH-saporin. Am J Physiol Regul Integr Comp Physiol 279: R729-R742.

Schreihofer AM, Stornetta RL, Guyenet PG (2000) Regulation of sympathetic tone and arterial pressure by rostral ventrolateral medulla after depletion of C1 cells in rat. J Physiol 529(Pt 1):221-236.

Simms AE, Paton JF, Pickering AE, Allen AM (2009) Amplified respiratory-sympathetic coupling in the spontaneously hypertensive rat: does it contribute to hypertension? J Physiol 587:597-610.

Stanek KA, Neil JJ, Sawyer WB, Loewy AD (1984) Changes in regional blood flow and cardiac output after L-glutamate stimulation of A5 cell group. Am J Physiol 246:H44-H51.

Swoap SJ, Weinshenker D, Palmiter RD, Garber G (2004) Dbh(-/-) mice are hypotensive, have altered circadian rhythms, and have abnormal responses to dieting and stress. Am J Physiol Regul Integr Comp Physiol 286:R108-R113.

Taxini CL, Takakura AC, Gargaglioni LH, Moreira TS (2011) Control of the central chemoreflex by $\mathrm{A} 5$ noradrenergic neurons in rats. Neuroscience 199:177-186.

Taxini CL, Puga CC, Dias MB, Bicego KC, Gargaglioni LH (2013) lonotropic but not metabotropic glutamatergic receptors in the locus coeruleus modulate the hypercapnic ventilatory response in unanaesthetized rats. Acta Physiol (Oxf) 208:125-135.

Toledo C, Andrade DC, Lucero C, Schultz HD, Marcus N, Retamal M, Madrid C, Del Rio R (2017) Contribution of peripheral and central chemoreceptors to sympatho-excitation in heart failure. J Physiol 595:43-51.

Vianna DM, Carrive P (2010) Cardiovascular and behavioural responses to conditioned fear and restraint are not affected by retrograde lesions of $\mathrm{A} 5$ and $\mathrm{C} 1$ bulbospinal neurons. Neuroscience 166:1210-1218.

Viemari JC, Hilaire G (2003) Monoamine oxidase A-deficiency and noradrenergic respiratory regulations in neonatal mice. Neurosci Lett 340:221-224.

Viemari JC, Bevengut M, Coulon P, Hilaire G (2004a) Nasal trigeminal inputs release the $A 5$ inhibition received by the respiratory rhythm generator of the mouse neonate. J Neurophysiol 91:746-758.

Viemari JC, Bevengut M, Burnet $\mathrm{H}$, Coulon $\mathrm{P}$, Pequignot JM, Tiveron MC, Hilaire G (2004b) Phox2a gene, A6 neurons, and noradrenaline are essential for development of normal respiratory rhythm in mice. J Neurosci 24:928-937.

Woodruff ML, Baisden RH, Whittington DL (1986) Effects of electrical stimulation of the pontine A5 cell group on blood pressure and heart rate in the rabbit. Brain Res 379:10-23.

Zoccal DB, Simms AE, Bonagamba LG, Braga VA, Pickering AE, Paton JF, Machado BH (2008) Increased sympathetic outflow in juvenile rats submitted to chronic intermittent hypoxia correlates with enhanced expiratory activity. J Physiol 586:3253-3265.

Zoccal DB, Bonagamba LG, Paton JF, Machado BH (2009) Sympathetic-mediated hypertension of awake juvenile rats submitted to chronic intermittent hypoxia is not linked to baroreflex dysfunction. Exp Physiol 94:972-983. 